\title{
Rationale use of Thalidomide in erythema nodosum leprosum - A non-systematic critical analysis of published case reports
}

\author{
Pugazhenthan Thangaraju[1], Sajitha Venkatesan ${ }^{[2],}$ \\ Meenalotchini Gurunthalingam ${ }^{[3]}$, Shoban Babu ${ }^{[4]}$ and Tamilselvan $T^{[5]}$
}

[1]. Department of Pharmacology, All India Institute of Medical Sciences, Raipur, Chhattisgarh, India.
[2]. Department of Microbiology, All India Institute of Medical Sciences, Raipur, Chhattisgarh, India.
[3]. Department of Pharmacology, All India Institute of Medical Sciences, Raipur, Chhattisgarh, India.
[4]. Department of Pharmacology, All India Institute of Medical Sciences, Jodhpur, Rajasthan, India.

[5]. School of information technology, SRM university, Sikkim, India.

\begin{abstract}
Introduction: Thalidomide is an anti- tumor necrosis factor alpha (TNF-a) drug used mainly in the management of moderate to severe form of Erythema Nodosum Leprosum (ENL). Because of its teratogenic potential it has to be used under proper supervision. Our critical analysis tries to look into the rationale with which it has been used by means of case reports on lepra reaction. Methods: We looked for the case reports between December 2005 to June 2019 in databases like Pubmed, Embase and other relevant resources. We used search words like "erythema nodosum leprosum(ENL)", "thalidomide", "case report" in different combinations to get relevant reports that focus on thalidomide usage atleast once at any time point during management. The information extracted were indication of thalidomide use, dose, response, outcome, complication if any, along with all the demographic details and geographical distribution. Results: We found 41 case reports eligible for analysis. The information was critically evaluated. From the analysis it was found that 7 of the case report mentioned the exact indication, 4 case report showed irrational use of thalidomide in the case of neuritis without use of steroids, 7 showed proper use of Clofazimine prior to thalidomide initiation, 26 case report showed case report of rationale dose range and in 4 case reports clofazimine was used prior to thalidomide along with the rational dose of thalidomide. Conclusions: This analysis helps to guide the rationale use of thalidomide focussing on few important points that anyone should keep in mind while managing a case of ENL.
\end{abstract}

Keywords: ENL. Management. Severity. Thalidomide. Rationale. Usage.

\section{INTRODUCTION}

Erythema Nodosum leprosum (ENL) or type 2 lepra reaction is a serious and difficult to manage immunological activity seen in intermediate borderline lepromatous (BL) and the polar lepromatous leprosy (LL). ENL may present as multiple acute episodes or chronic $\mathrm{ENL}^{1,2}$. In a large cohort study in India, less than $10 \%$ of patients had only a single episode of ENL while around $62.5 \%$ had chronic occurring ENL ${ }^{2}$. Various manifestations of ENL include generalized, cutaneous and peripheral nerve involvement. The

\footnotetext{
Corresponding author: Dr. Pugazhenthan Thangaraju.

e-mail: drpugal23@gmail.com

(D) https://orcid.org/0000-0002-4090-2004

Received 3 October 2019

Accepted 24 June 2020
}

cutaneous manifestations are widespread crops of erythematous inflamed nodules and papules, which are superficial or deep, that wean off periodically ${ }^{3}$. Ulcerated, necrotic, pustular and bullous forms have also been described. Some nodules lead to fibrosis and scarring $^{3}$. Neuritis present with painful and enlarged nerves with functional impairment. Generalized systemic illness includes high fever and prostration due to immune complex mediated complement activation. Erythema nodosum leprosum is a type III Arthus antigen antibody reaction that causes generalised symptoms throughout the body system ranging from mild to severe spectrum. Edema and transient proteinuria may also occur. Eye involvement in the form of iritis and episcleritis can occur in some cases and may lead to loss of vision. Other features such as pain, photophobia and lacrimation may be absent in contrast to the other bacterial infections of eye ${ }^{3}$. Orchitis, lymphadenopathy, organomegaly, joint involvement, dactylitis and bone tenderness over the tibia, are well recognized and 
documented features of ENL. The chronic type of ENL is difficult to manage in the peripheral set up and always needs referral to tertiary or higher centers. There is a general opinion among the treating physicians that $1 \log$ reduction of bacilli will take 1 year for bacilli to be cleared and in most of the cases the ENL severity correlates with this bacillary index ${ }^{4}$. This chronicity also has an impact on the psychological status of the patients with lepra reaction that will aggravate the existing conditions ${ }^{5}$.

\section{Currently available treatment for ENL}

The main objectives in the management of ENL are to control the inflammation, pain relief and prevention of further episodes ${ }^{6}$. Mild cases are treated with Non Steroidal Antiinflammatory Drugs(NSAIDs) like aspirin and paracetamol. In moderate and severe cases, corticosteroids are the mainstay of treatment. The most commonly used corticosteroid is oral prednisolone. Oral Prednisolone is started at the dose of $40-60 \mathrm{mg} / \mathrm{kg}$ body weight/ day to a maximum of $1 \mathrm{mg} / \mathrm{kg} /$ body weight/ day. The dose is tapered gradually with the improvement of symptoms up to $5 \mathrm{mg}$ and stopped once the reaction subsides ${ }^{7}$.Majority of the patients require multiple courses of prednisolone due to the natural history of the disease ${ }^{2}$. In steroid dependency or steroid induced complications, Clofazimine is used. Clofazimine is a dye acting as an anti-inflammatory and antimicrobial agent. But it has a slower onset of action ${ }^{8}$. Clofazimine at a dose of up to $300 \mathrm{mg}$ daily can be given to control ENL. This higher dose should not be continued for more than 12 months. Treatment with thalidomide has been useful to reduce the prednisolone requirement of patients with chronic ENL ${ }^{9}$. Due to its teratogenicity potential, Thalidomide should be used with extreme caution in reproductive age group of both the sexes even though WHO doesnot recommend $\mathrm{it}^{10}$. The Risk Evaluation and Mitigation Strategy (REMS) program adopted by the USFDA has been useful in preventing pregnancies in women taking thalidomide ${ }^{11}$. Because of its good efficacy in managing the severe cases of ENL, it is still being used as a drug in emergency conditions where steroids or other drugs are contraindicated. In this background, ensuring proper and rational use of thalidomide becomes the responsibility of the treating physician.

Rational use of medicines in this context may be defined as the patients receiving medications relevant to their clinical needs, in doses that meet their own individual requirements, for an adequate period of time, and at the lowest cost to them and their community. It is also mandatory to know the 12 key interventions that the WHO advice for promotion of rational use of drugs ${ }^{12}$ like establishing national level multidisciplinary body for coordinating the policies on medicine use, using available clinical guidelines effectively, developing and using the medicines enlisted in the National List of Essential Medicines, forming committees for drugs and therapeutics in the district hospitals, including the problem-based pharmacotherapy in the undergraduate curriculum, to continue inservice medical education as a requirement for obtaining license for practising, routinely supervising and auditing and obtaining feedback from the practitioners, using information of medicines independently, creating awareness and educating the public about medicines, avoiding financial incentives perversely, enforcing appropriate regulation and ensuring availability of staff and medicines by sufficient funding by the Government.
So to know the rationale behind the treatment, there is an increasing need to describe the various treatment procedures that will develop the understanding of readers of published content and treatment protocol. It is also mandatory to describe the type of drug used, route of administration, approved dosage and frequency, possible side effects. Case reports were studied in this review as detailed information regarding treatment course and characteristics are mentioned irrespective of severity and presentation of ENL. It also helped us explore if drug use was rational. Moreover, case reports are not planned and structured study as in the case of randomised clinical trials. They are done based upon the knowledge and experience of the treating physician which helps us get an insight about how far the treating physicians are aware of the treatment protocol and guidelines while using Thalidomide for ENL.

\section{METHODS}

\section{Search strategy}

We identified case reports of the following bibliographic databases MEDLINE, Embase and Web of Science. In PubMed the case reports were identified by using searches included as (lepra[All Fields] AND reaction[All Fields] AND ("thalidomide" [MeSH Terms] OR "thalidomide"[All Fields])) AND (Case Reports[ptyp] AND ("2005/01/01" [PDAT] : "2019/06/30"[PDAT])) (("erythema nodosum"[MeSH Terms] OR ("erythema"[All Fields] AND "nodosum"[All Fields]) OR "erythema nodosum"[All Fields]) AND leprosum[All Fields] AND ("thalidomide" [MeSH Terms] OR "thalidomide"[All Fields])) AND (Case Reports[ptyp] AND ("2005/01/01"[PDAT] : "2018/06/30"[PDAT])). In addition, we also searched references of the studies of screened articles to extract information about relevant articles.

\section{Study selection}

In the first step, titles and abstracts of the articles were reviewed and irrelevant articles were excluded. In the next step, full texts of the selected articles were screened as per inclusion and exclusion criteria.

\section{Inclusion criteria}

(a) Patients: any age group and both genders

(b) Intervention: thalidomide used at anytime point

(c) Type of study: case reports/case series.

\section{Exclusion criteria}

Articles of ENL where thalidomide is not used were excluded from the study.

\section{Data extraction (selection and coding)}

Two reviewers have independently screened the titles and abstracts of the references retrieved in the searches to identify potential reports that meet the inclusion criteria, before screening the full-text papers. The information on authors, patient demographic like age, sex, area of residence, clinical aspects of disease, investigation and special investigation, diagnosis and the treatment of the conditions with outcome, additional remarks if any and their year of publication and journal were extracted. We focused only on the treatment part which contains Thalidomide and the points relevant to it. 
Regarding thalidomide the information's extracted include rational indication, dose at start of reaction and average daily dose, and outcome of the treatment. The outcome is called "responded" if there is clinical response to the use of thalidomide in reversing the severity of symptoms of reaction and complete remission from the start of initiation of thalidomide and sustained for several months to year. Rationale use of thalidomide is based on the guidelines of various countries $\left(\mathrm{Brazil}^{13}\right.$, Japan ${ }^{14}$, $\mathrm{USA}^{14}$ ) and reaction management program adopted. Japan adopted the USA guideline with little modification with respect to the Dose. Regarding Brazil, even though strict special recommendation has been in management protocol of ENL, still cases of embryopathy and baby born with phacomelia is seen ${ }^{13}$. The countries in Europe also follow similar recommendation of dosage of $300 \mathrm{mg}$ and indications as given by the recommendation by USA and its manufacturer ${ }^{14}$.

The factors essential for rationality are the proper indication of starting the drug and the approved dose as per the symptoms. There are exceptions where it is directly started based on case to case variation. The approved indication and the dose for treatment of severe ENL is $100-400 \mathrm{mg}$ /day in divided doses shown in $(\text { Table 1) })^{14}$.

\section{Statistical analysis}

All the information from the case reports were extracted in the excel sheet. We focused on the information pertaining to thalidomide use, like indication, dose and its combination and adverse events. Data was presented in numbers and percentages.

\section{RESULTS}

A total of case report/series reported from 01-01-2005 to 30-06-2019 were 35 from PubMed and 9 from other series. A total of 34 case report/ series which met the inclusion criteria were screened and selected for analysis. There was a total of 41 individual cases (Figure 1) reported in the 34 available case report/ series. Leon et al had 2 cases $^{15}$, Fogagnolo et al had 2 cases $^{16}$, Rahul nagar et al had 3 cases $^{17}$ and Rattan et al had 4 cases $^{18-20}$, in their case series summing up to 41 case reports in 34 case series.

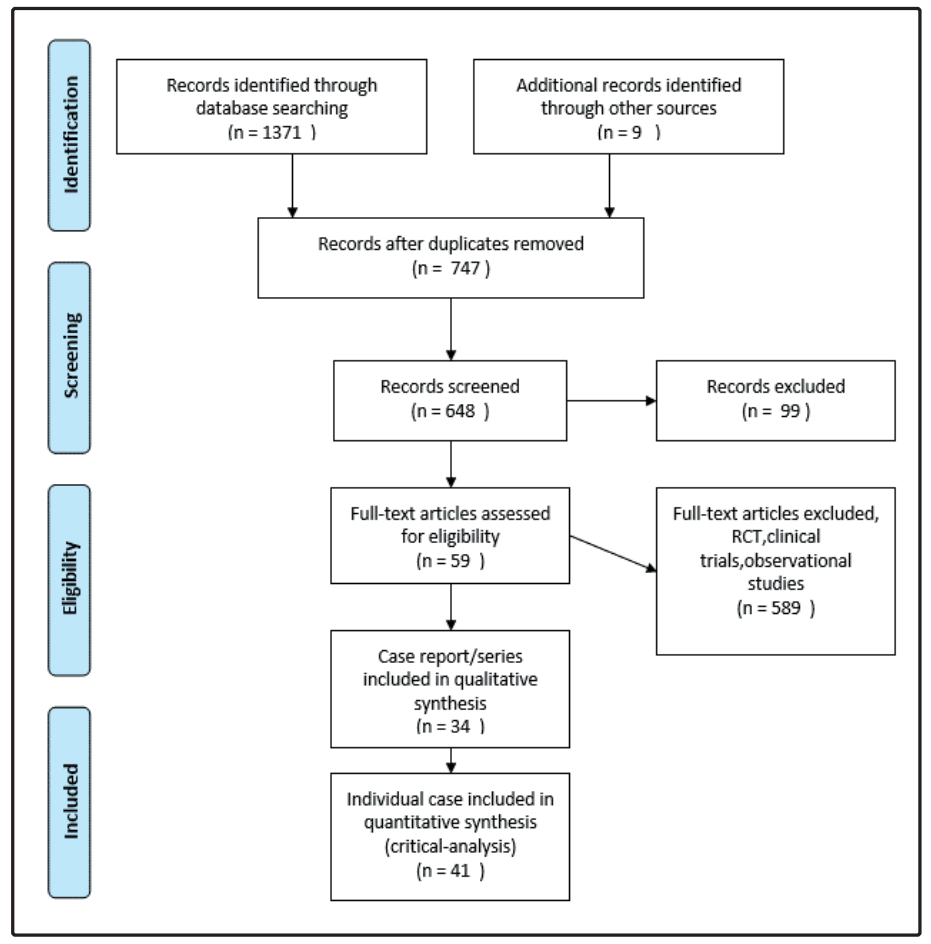

FIGURE 1: Flow diagram of case reports included in the review(PRISMA).

Out of the 41 cases reported (Table 2), 30 were male and 11 were female with 26 reports are from India and the remaining 15 were from outside India.The distribution of 7 reports from Brazil, 1 from Phillipines, South East Asia, USA, Columbia, Netherlands, China and Japan each (Table 2/ Supplementary Figure 1).

Regarding the age distribution (Table 2), there were no cases reported in the age group of 1-10 years. The highest number of 13 cases were reported in the age group of 31-40 years, out of which 9 were males and 4 were females. The next highest number of 11 cases were detected in the age group of $21-30$ years where 10 were male and 1 was female. 5 cases were detected in the age group of 41-50

TABLE 1: Approved indication and dosage ${ }^{14}$.

INDICATIONS

Acute treatment- cutaneous manifestations- moderate to severe erythema nodosum leprosum (ENL).

Not indicated as monotherapy - Presence of moderate to severe neuritis.

Maintenance therapy- cutaneous manifestations of ENL recurrence

DOSAGE AND ADMINISTRATION

100 to $300 \mathrm{mg} /$ day OD or in divided dose.

Initiate dosing at the low end of the dose range for less weighing patient.

Higher dosage range - severe cutaneous ENL reaction, or in those who have previously required higher doses to control the reaction (up to $400 \mathrm{mg} /$ day)

Concomitant use of corticosteroids - moderate to severe neuritis.

Continue dosing at least 2 weeks.

Patients may then be reduced of medication in $50 \mathrm{mg}$ decrements every 2 - 4 weeks.

Reduction should be attempted every 3 - 6 months and in reduction of $50 \mathrm{mg}$ every 2 to 4 weeks. 
years where 4 were male and 1 was female. 6 cases were detected in the age group of 51-60 years where there was equal distribution among both sexes accounting for 3 each. 3 cases (all male) were detected in 61- 70 years age group and 2 cases ( all female ) were detected in the age group of 11-20 years.

With respect to the Bacterial Index (BI)(Table 2), it was not mentioned in 18 cases. Out of the remaining 23 cases, BI was mentioned as 1+, 2+, 3+, 4+,5+ and $6+$ in $1,1,3,4,4,10$ cases respectively.

With respect to rational use of Clofazimine and thalidomide (Supplementary Table 1) only 7 cases has been found out to be a rationale. 6 out of the 7 cases were from India and 1 from outside India.

With respect to the rational use of thalidomide (Table 3) in proposed dosage 26 cases has been found out to be a rationale. Out of the 26 cases 18 were reported from India and the remaining 8 from outside India. There were two cases of ENL in which thalidomide is planned as per the existing protocol and they were from India.(Table 3)

The major indication for starting thalidomide (Table 4) is severe ENL or recurrent ENL. This was mentioned only in 7 cases and the in the rest of the 35 cases, there was no mention of the severity of ENL but merely ENL.

With relevance to neuritis and thalidomide (Table 4), out of the 41 cases, there was no neuritis in 21 cases. In 16 cases, thalidomide had been prescribed along with steroids in a rationale indication. In 4 cases, steroids were not given along with thalidomide.

The duration of treatment with thalidomide is divided into treatment less than 3 months, for 3 months and more than 3 months. Generally the range of duration falls between 3 months to 6 months based on the dosage the drugs was being started and the tapering once in two weeks. As general 3 months is ideal duration a patient can respond after due tapering and stoppage. But it depends on case to case basis (Table 4).

Regarding the dose (Table 4), Out of the 41 cases studied, the dose of thalidomide was not mentioned in detail in 15 cases. The dose of $100 \mathrm{mg}, 150 \mathrm{mg}, 200 \mathrm{mg}, 300 \mathrm{mg}$ and $400 \mathrm{mg}$ was given in 3 cases, 1 patient, 2 cases, 18 cases and in 2 cases respectively.

Out of the 41 cases 24 cases responded to the treatment with thalidomide whereas in 17 cases thalidomide was stopped (Table 4).

The reasons for stopping Thalidomide may be due to drug intolerance, pregnancy, non responsiveness to the drug or adverse drug reactions.

Out of the total 41 cases, thalidomide was stopped in 17 patients after starting the treatment (Table 4). In 8 patients there was no response to Thalidomide and there was subsequent use of other drugs like Methotrexate, Etanercept, Azathioprine and Infliximab were used. Thalidomide was stopped due to peripheral neuropathy in 2 patients and due to deep vein thrombosis (DVT) in 4 patients. Among the 4 patients who developed DVT due to thalidomide, one patient was given Etanercept. One patient became pregnant after the start of the treatment with thalidomide and therefore the drug
TABLE 2: Demographic details.

\begin{tabular}{|c|c|}
\hline Demographic parameters & Number \\
\hline \multicolumn{2}{|l|}{ Age } \\
\hline $1-10$ & 0 \\
\hline $11-20$ & 2 \\
\hline $21-30$ & 11 \\
\hline $31-40$ & 13 \\
\hline $41-50$ & 5 \\
\hline $51-60$ & 6 \\
\hline $61-70$ & 3 \\
\hline \multicolumn{2}{|l|}{ Sex } \\
\hline Male & 30 \\
\hline Female & 11 \\
\hline \multicolumn{2}{|l|}{ Geographical distribution } \\
\hline India & 26 \\
\hline Brazil & 7 \\
\hline Philippines & 1 \\
\hline South east Asia & 1 \\
\hline USA & 1 \\
\hline Micronesia & 1 \\
\hline Columbia & 1 \\
\hline Netherlands & 1 \\
\hline China & 1 \\
\hline Japan & 1 \\
\hline \multicolumn{2}{|l|}{ Bacillary index } \\
\hline NA & 18 \\
\hline $1+$ & 1 \\
\hline $2+$ & 2 \\
\hline $3+$ & 3 \\
\hline $4+$ & 3 \\
\hline $5+$ & 4 \\
\hline $6+$ & 10 \\
\hline
\end{tabular}

NA: Not Available.

was withdrawn owing to its teratogenic effect. One patient died during the course of treatment not due to thalidomide but due to associated septicaemia.

Out of all the case reports, only 4 case reports met the rational criteria for usage of Thalidomide in the recommended dose and was used after using Clofazimine. All the 4 case reports were from India.(Table 3/Supplementary Figure 1).

\section{DISCUSSION}

This is the first analysis of its kind which focuses on the rational use of thalidomide in ENL in the published literature till 30-06-2019. The analysis was made using the case reports/series. The objective of selecting case report is that the rationale use can be only assessed in the case report from various part of the world. As already commented, case report are not a planned work with which a physician manages. The treating physicians manage the case as per their knowledge in the existing scenario and protocol and guideline but not necessarily to compile data as in the case of planned structured studies. Hence, we felt critical analysis would help in bringing out information at the treating level of health professionals.

According to the WHO's definition of rational drug, the drug should be enlisted in the National List of Essential Medicines and 
TABLE 3: Rational use of Thalidomide along with Clofazimine with reference to individual countries.

\begin{tabular}{|c|c|c|c|c|c|c|}
\hline \multirow[t]{2}{*}{ S.no } & \multirow[t]{2}{*}{ Reference } & \multirow[t]{2}{*}{ Country } & \multirow[t]{2}{*}{$\begin{array}{l}\text { Sample } \\
\text { size }\end{array}$} & \multirow[t]{2}{*}{ Treatment } & \multirow[t]{2}{*}{$\begin{array}{l}\text { Clofazamine } \\
Y=1 N=0\end{array}$} & \multirow[t]{2}{*}{$\begin{array}{l}\text { Rationale- } \\
\text { (Thalidomide } \\
\text { clofazamine) } \\
\text { Interpretation }\end{array}$} \\
\hline & & & & & & \\
\hline 1 & Fogagnolo et $\mathrm{al}^{16}$ & Brazil & 2 & Thalidomide $300 \mathrm{mg} /$ day, Prednisolone $80 \mathrm{mg} /$ day & 0 & $\begin{array}{l}\text { No-Not } \\
\text { always } \\
\text { mandatory }\end{array}$ \\
\hline \multirow[t]{7}{*}{2} & Rahul nagar ${ }^{17}$ & India & 3 & I- Prednisolone 40 mg/day & 1 & Yes \\
\hline & & & & clofazimine 300 mgs/day & & \\
\hline & & & & thalidomide was tapered below 100 mgs/day. & & \\
\hline & & & & $\begin{array}{l}\text { Il- Prednisolone } 40 \mathrm{mgs} / \text { day, clofazimine } 100 \mathrm{mgs} \\
\text { three times a day prednisolone in higher doses of } 60 \\
\text { mgs/day. }\end{array}$ & 1 & \\
\hline & & & & Two successive thalidomide courses were also found & & \\
\hline & & & & $\begin{array}{l}\text { III- Prednisolone } 40 \mathrm{mgs} / \text { day,clofazimine } 100 \mathrm{mgs} \\
\text { three times a day prednisolone in higher doses of } 60 \\
\mathrm{mgs} / \mathrm{day} \text {. }\end{array}$ & & \\
\hline & & & & Two successive thalidomide courses were also found & 1 & \\
\hline \multirow[t]{4}{*}{3} & Rattan et $a^{18}$ & India & 4 & Thalidomide 100mg/thrice a day + MDT - MB & 0 & No \\
\hline & & & & Thalidomide $100 \mathrm{mg} /$ thrice a day + MDT - MB & & \\
\hline & & & & Thalidomide 100mg/thrice a day + MDT - MB & & \\
\hline & & & & Thalidomide 100mg/thrice a day + MDT - MB & & \\
\hline 4 & Mahajan et al ${ }^{21}$ & India & 1 & $\begin{array}{l}\text { Treatment restarted with prednisone }(60 \mathrm{mg} / \mathrm{day}) \text {, } \\
\text { clofazimine }(100 \mathrm{mg} \text { three times/day), rifampicin ( } 600 \mathrm{mg} \\
\text { once a month), thalidomide ( } 100 \mathrm{mg} \text { three times/day) }\end{array}$ & 1 & Yes \\
\hline \multirow[t]{3}{*}{5} & Jitendra ssv et al22 & India & 1 & Prednisolone $1 \mathrm{mg} / \mathrm{kg} /$ day & 1 & Yes \\
\hline & & & & $\begin{array}{l}\text { Clofazimine } 300 \mathrm{mg} / \mathrm{day} \text { for six months and } 100 \mathrm{mg} / \\
\text { day for another six months }\end{array}$ & & \\
\hline & & & & Thalidomide 200 mg/day (STOPPED) & & \\
\hline 6 & $\mathrm{~T}$. Narang et $\mathrm{al}^{23}$ & India & 1 & $\begin{array}{l}\text { Started rationale dose but patient not tolerated } \\
\text { (apremilast) }\end{array}$ & 1 & Yes \\
\hline 7 & Barman et $\mathrm{al}^{24}$ & India & 1 & MDT, Thalidomide - 100mg, T. Prednisolone. & 0 & No \\
\hline 8 & Richards ${ }^{25}$ & $\begin{array}{l}\text { Pt from } \\
\text { Micronesia- } \\
\text { treated } \\
\text { at Dallas, } \\
\text { Texas }\end{array}$ & 1 & MDT, Prednisolone 60mg/day, Thalidomide - 100mg & 0 & $\begin{array}{l}\text { No, Not } \\
\text { always } \\
\text { mandatory }\end{array}$ \\
\hline 9 & Rodriguez ${ }^{26}$ & Colombia & 1 & MDT, Thalidomide $300 \mathrm{mg} /$ day, Prednisolone $50 \mathrm{mg} /$ day & 0 & $\begin{array}{l}\text { No, Not } \\
\text { always } \\
\text { mandatory }\end{array}$ \\
\hline 10 & Verma et $\mathrm{al}^{27}$ & India & 1 & $\begin{array}{l}\text { MDT, Prednisolone } 40 \mathrm{mg} / \mathrm{day} \text {, Thalidomide } 100 \mathrm{mg} \\
\text { TDS, Azathiprine } 50 \mathrm{mg} / \mathrm{twice} \text { daily. }\end{array}$ & 0 & No \\
\hline 11 & Verma et $\mathrm{al}^{27}$ & India & 1 & $\begin{array}{l}\text { MDT,Prednisolone } 1 \mathrm{mg} / \mathrm{kg} / \text { day, Thallidomide } 100 \mathrm{mg} \\
\text { QID for } 4 \text { months }\end{array}$ & 0 & No \\
\hline 12 & Yogeesh HR et $a^{28}$ & India & 1 & MDT, Prednisolone 30mg, Thalidomide 100mg TDS, & 0 & No \\
\hline 13 & Faber et $\mathrm{al}^{29}$ & Netherlands & 1 & $\begin{array}{l}\text { MDT, Steroids, Thalidomide } 300 \mathrm{mg} \text {, Pentoxiphylline } \\
400 \mathrm{mg} \text {, Finally, Infliximab } 5 \mathrm{mg} / \mathrm{kg} \text {. }\end{array}$ & 0 & $\begin{array}{l}\text { No, Not } \\
\text { always } \\
\text { mandatory }\end{array}$ \\
\hline 14 & $\begin{array}{l}\text { Hebe Petiti-Martin } \\
\text { et } \mathrm{al}^{30}\end{array}$ & Spain & 1 & $\begin{array}{l}\text { MDT, Prednisolone, Thalidomide - } 150 \mathrm{mg} / \text { day } \\
\text { [stopped], Enoxeparin, Acenocoumoral }\end{array}$ & 0 & $\begin{array}{l}\text { No, Not } \\
\text { always } \\
\text { mandatory }\end{array}$ \\
\hline
\end{tabular}


Thangaraju P et al. - Thalidomide Rationale

TABLE 3: Continuation.

\begin{tabular}{|c|c|c|c|c|c|c|}
\hline 15 & Vetrichevel et al ${ }^{31}$ & India & 1 & $\begin{array}{l}\text { MDT, Corticosteroids, Thalidomide } 300 \mathrm{mg} / \text { day then } \\
\text { stopped, LMWheparin, Warfarin for } 6 \text { months. }\end{array}$ & 0 & No \\
\hline 16 & $\begin{array}{l}\text { Sundeep chowdary } \\
\qquad \text { et }\left.^{32}\right|^{32}\end{array}$ & India & 1 & $\begin{array}{l}\text { Prednisolone ( } 40-80 \mathrm{mg} \text { ) } \\
\text { Etanercept ( } 50 \mathrm{mg} / \text { week) subcutaneously. } \\
\text { Clofazimine ( } 300 \mathrm{mg} \text { daily), } \\
\text { Thalidomide (starting dose: } 300 \mathrm{mg} \text { daily), } \\
\text { Minocycline ( } 100 \mathrm{mg} \text { daily), } \\
\text { Clarithromycin ( } 1 \mathrm{~g} \text { daily), } \\
\text { Ofloxacin ( } 400 \mathrm{mg} \text { daily), } \\
\text { Pentoxifylline ( } 400 \mathrm{mg} \text { three times daily), } \\
\text { Azathioprine ( } 150 \mathrm{mg} \text { daily; later increased to } 300 \mathrm{mg} \text { ) }\end{array}$ & 1 & No \\
\hline 17 & $\begin{array}{l}\text { Julia Rocha Silva } \\
\text { Santos et al }{ }^{33}\end{array}$ & Brazil & 1 & $\begin{array}{l}\text { Thalidomide (100- } 300 \mathrm{mg} / \mathrm{day}) \\
\text { prednisone at ( } 20-40 \mathrm{mg} / \mathrm{day}) \\
50 \mathrm{mg} \text { of etanercept SC. } \\
\text { Thalidomide was interrupted } \\
\text { Prednisone was continued at a dose of } 10 \mathrm{mg} / \mathrm{day}\end{array}$ & 0 & $\begin{array}{c}\text { No, Not } \\
\text { always } \\
\text { mandatory }\end{array}$ \\
\hline 18 & Gulanikar et al ${ }^{34}$ & India & 1 & Prednisolone 30mg . Thalidomide 100mg QID & 0 & No \\
\hline 19 & Yamaghuchi et $\mathrm{al}^{35}$ & Japan & 1 & PSL $15-55$ mg/day,Thalidomide $100-300$ mg/day & 0 & $\begin{array}{l}\text { No, Not } \\
\text { always } \\
\text { mandatory }\end{array}$ \\
\hline 20 & Sharma et $\mathrm{al}^{36}$ & India & 1 & $\begin{array}{l}\text { MDT } \\
\text { Prednisolone } 60 \mathrm{mg} / \mathrm{d} \text {, } \\
\text { Ibuprofen } 400 \mathrm{mg} \text { t.i.d. } \\
\text { colchicine } 0.5 \mathrm{mg} \text { b.i.d. } \\
\text { thalidomide } 100 \mathrm{mg} \text { bd and stopped }\end{array}$ & 0 & No \\
\hline & with respect to use of & domide $\mathrm{i}$ & & & & \\
\hline 21 & $\begin{array}{l}\text { Satyendra Kumar } \\
\text { Singh et } \mathrm{al}^{37}\end{array}$ & & & Plan for Thalidomide in desired rationale dose & & \\
\hline 22 & $\begin{array}{c}\text { Prasan Kumar Panda } \\
\text { et al }{ }^{38}\end{array}$ & & & Plan for Thalidomide in desired rationale dose & & \\
\hline
\end{tabular}

TABLE 4: Details of Thalidomide usage.

\begin{tabular}{|c|c|c|c|}
\hline Thalidomide & Number & Thalidomide & Number \\
\hline Severity mentioned & & $150 \mathrm{MG}$ & $1(2.44)$ \\
\hline ENL & $35(83)$ & 200MG & $2(4.88)$ \\
\hline Severe ENL & $7(17)$ & 300MG & 18(43.90) \\
\hline Duration of treatment & & 400MG & $2(4.88)$ \\
\hline Not mentioned & $15(35.71)$ & Outcome & \\
\hline$<3$ Months (treatment stopped) & $6(14.29)$ & Responded & $24(59)$ \\
\hline-3 months & $17(40.48)$ & Stopped & $17(41)$ \\
\hline$>3$ months & $3(7.14)$ & Reasons for stopping Thalidomide & \\
\hline Thalidomide and steroids indications & & NR-other drugs used & $8(47)$ \\
\hline No neuritis & $21(51)$ & Peripheral neuropathy & $2(12)$ \\
\hline Neuritis- Thalidomide + steroids & $16(39)$ & DVT & $4(23)$ \\
\hline Neuritis- Thalidomide alone & $4(9.75)$ & Pregnancy & $1(6)$ \\
\hline Thalidomide dose & & Intolerance & $1(6)$ \\
\hline Not mentioned & $15(36.58)$ & Died & $1(6)$ \\
\hline $100 M G$ & $3(7.32)$ & & \\
\hline
\end{tabular}


awareness should be created among the public regarding its use. As per the analysis, it was found that thalidomide is enlisted in the national list of essential medicines ${ }^{39}$ but not for the ENL indication. But awareness has been created to those specifically involved in the management of lepra reactions through country programme and the institutes managing the severe cases of ENL.

The WHO does not support the approved use of thalidomide in the management of severe ENL as thalidomide being a proved teratogenic ${ }^{10}$. Although the legislations and laws cover for restricted sale and supply of thalidomide, dispensation of thalidomide being active in Brazil has caused recent registering of cases of thalidomide embryopathy ${ }^{40,41}$.

But it is off the document that the countries harbouring leprosy burden, thalidomide is being used with all necessary precautions for the treatment of ENL as per the indication. Various countries like the United States of America, the European countries, India, Brazil ${ }^{42}$ and $\operatorname{Japan}^{43}$ use Thalidomide for the treatment of ENL following the US- FDA ${ }^{44}$ recommendation ie. Thalidomide in a dose of 100-300 $\mathrm{mg} .400 \mathrm{mg}$ of thalidomide given in severe cases of ENL.

It is being used for this specific indication only in the speciality centres that was approved for usage with proper registries like Central Leprosy Teaching And Research Institute (Government of India), many NGO under the leprosy mission, Bombay projects etc.

From the total 41 cases analysed, it was found that there was a male predominance over the females where $73 \%$ i.e. 30 were males and $27 \%$ i.e. 11 were females. A major chunk of $67 \%$ i.e. 26 cases were reported from India followed by Brazil with 7 cases and the rest 8 cases have been reported from various other parts of the world.

When we consider the age distribution of severe ENL reported, it was found that the majority of cases were reported in the age group belonging to 21-40 years again with a male preponderance. There were a total of 24 cases in the age group of 21-40 years out of which 11 were reported in 21-30 years of age group and 13 in 31-40 years of age group. It might be due to the fact that the immune system namely the humoral component is active in the age group of 21-40 years leading to a majority of ENL cases reported in this age group. It may also be due to the fact that it is productive age group where the patients may be losing their productive days due to restricted movements which may lead to decrease in their ability to earn income. It is to be noted from the case studies that higher the Bacterial Index (BI) higher is the chance of recurrent ENL and it is an already established fact and has been published in literatures.

Out of the 41 case studies, only in 7 cases the severity of ENL has been mentioned (severe/ recurrent). In the remaining 34 cases there is no mention of severity. As per the guidelines/protocol, thalidomide is indicated only in severe or recurrent ENL. According to this analysis it is clear that there is need for proper mentioning of the indication of the severity of ENL as it is the deciding criteria for using thalidomide.

Thalidomide should be used in case of neuritis only along with steroids $^{44}$. In our study we found that out of the total 20 cases where peripheral neuritis was reported, thalidomide was used along with prednisolone in 16 cases. In the remaining 4 cases thalidomide was used alone against the guidelines where it should be used with corticosteroids.
The approved dose range is between 100 to $400 \mathrm{mg}$ as a divided dose $^{44}$. The dose of thalidomide was not mentioned in 15 cases. This should be always mentioned as it will help the clinicians and the readers to find whether it is because of non availability during the course of treatment, or non responsiveness to low dose range of approved dosage so the case is managed with alternative drugs and other possible reasons. The protocol of reduction of doses depends upon the clinical improvement on a case to case basis. The dose may be reduced by $50 \mathrm{mg}$ decrements every $2-4$ weeks. This reduction should be attempted every $3-6$ months ${ }^{44}$.

According to the treatment guidelines management of ENL by $\mathrm{WHO}^{45}$, a case of severe of ENL should be first treated with Prednisolone in adequate doses. If the patient did not respond to prednisolone then the patient is put on Clofazimine only or in most cases a combination of Clofazimine and prednisolone regimen. In cases where the patients do not respond to either Clofazimine or Clofazimine and prednisolone combination, then the patients are considered for treatment with thalidomide. The Clofazimine is used as one capsule of $100 \mathrm{mg} 3$ times a day for initial 3 months followed by one capsule of $100 \mathrm{mg} 2$ times a day for the next 3 months and finally one capsule of $100 \mathrm{mg}$ once a day for next 3 months. Even though Clofazimine is less potent than steroids and often takes $4-6$ weeks to develop its full effect; it is extremely useful in reducing or withdrawing corticosteroids in patients who have become dependent on them. Total duration of Clofazimine therapy should not exceed 12 months.

Among the 41 case studies, Clofazimine was started or given in only 7 cases. In 26 case studies thalidomide was used rationally with respect to dose. But among all the 26 cases where thalidomide was given rationally with respect to the dose, only 7 case studies showed that the patients were started with Clofazimine before using thalidomide. Regarding the usage of thalidomide after Clofazimine, it is the standard protocol being practiced in India unless contraindicated. Even among Indian studies, only 7 out of 18 cases followed the protocol of Clofazimine and thalidomide. In other countries, because of fairness in skin colour, Clofazimine is seldom used either in MDT regimine or in management of lepra reaction because of hyperpigmentation.

Out of the total 41 cases, thalidomide was stopped in 17 patients after starting the treatment. In 8 patients there was no response to Thalidomide and there was subsequent use of other drugs like Methotrexate, Etanercept, Azathioprine and Infliximab were used. Thalidomide was stopped due to peripheral neuropathy in 2 patients and due to deep vein thrombosis (DVT) in 4 patients. Among the 4 patients who developed DVT due to thalidomide, one patient was given Etanercept. One patient became pregnant after the start of the treatment with thalidomide and therefore the drug was withdrawn owing to its teratogenic effect. One patient died during the course of treatment not due to thalidomide but due to associated septicaemia. There was no mention of the precaution or advice of precaution which has to be given mandatorily to all female patients of reproductive age group.

The analysis of case report has widened our eyes in various aspect of erythema nodosum leprosum management. There is a need by the physcician who were instrumental in treating the 
reaction case for detailed description of case, categorise the severity and the treatment as per their severity scale. We also found that in spite of rationale usage of thalidomide also there are cases not responded with the approved dose and frequency explaining the strong immunological response or inflammation that needs other immunomodulatory and biologics. This analysis also shows a major gap in following the treatment guideline wherein the treating physicians are lacking the proper information regarding the use of thalidomide and clofazimine in the management of ENL or it is the severity of ENL that makes the physician not to wait with slower acting drug clofazimine and directly dispensed the thalidomide or non availability of clofazimine that warrents to use thalidomide. Hence there is a need to spread proper awareness among the treating physicians for treatment of severe cases of ENL. But in countries like Brazil, thalidomide is considered as the drug of choice for managing severe ENL at the time of initiating management. The same Brazilian health ministry also recommends Clofazimine and prednisolone. So country to country variability should also be taken into consideration.

From the analysis, we found that there is lacuna in the rational usage of thalidomide with respect to indication, dose and usage along with clofazamine and corticosteroids. But clofazimine usage depends upon geographical distribution based on its character of causing hyperpigmentation. So outside India it is seldom used and alternative of pentoxyfylline or minocycline is being tried. There is a need for proper guideline for usage of thalidomide and awareness should be created among the treating physicians for the same. If rationally used, thalidomide is a boon in the treatment of severe ENL.

\section{RECOMMENDATIONS}

- Case report pertaining to ENL should mention the severity scale of ENL

- Listing of other drugs used with proper dose and duration before starting thalidomide should be explained in detail.

- Proper use of steroids and thalidomide in case of neuritis should be stressed.

- Thalidomide with approved dose and frequency should be used.

- Usage of newer biologics in ENL should be sufficiently followed up.

\section{ACKNOWLEDGMENTS}

We offer our deepest thanks to the Dr Niranjan who provided support from the beginning till the completion of this study.

\section{AUTHORS' CONTRIBUTION}

PT: literature review, concept, manuscript editing. SV: conceptual input. MG: Drafting, writing the manuscript. SB: literature review. TT: literature review, Drafting.

\section{CONFLICT OF INTEREST}

The authors declare that there is no conflict of interest.

\section{REFERENCES}

1. Kumar B, Dogra S, Kaur I. Epidemiological characteristics of leprosy reactions: 15 years experience from north India. Int $\mathrm{J}$ Lepr Other Mycobact Dis. 2004;72(2):125-33.
2. Pocaterra L, Jain S, Reddy R, Muzaffarullah S, Torres O, Suneetha S, et al. Clinical course of erythema nodosum leprosum: an 11-year cohort study in Hyderabad, India. Am J Trop Med Hyg. 2006;74(5):868-79.

3. Pandhi $\mathrm{D}, \mathrm{Chhabra}$ N. New insights in the pathogenesis of type 1 and type 2 lepra reaction. Indian J Dermatol Venereol Leprol. 2013;79(6):739-49.

4. Saunderson P, Gebre S, Byass P. ENL reactions in the multibacillary cases of the AMFES cohort in central Ethiopia: incidence and risk factors. Lepr Rev. 2000;71(3): 318-24.

5. Negera E, Walker SL, Girma S, Doni SN, Tsegaye D, Lambert SM, et al. Clinico-pathological features of erythema nodosum leprosum: A case-control study at ALERT hospital, Ethiopia. PLoS Negl Trop Dis. 2017;11(10):e0006011.

6. Lockwood DN. The management of erythema nodosum leprosum: current and future options. Lepr Rev. 1996;67(4):253-9.

7. Steroids usage in lepra reaction. https://www.who.int/lep/ research/ Reactions.pdf. Retrieved on 23-03-2020.

8. Helmy HS, Pearson JM, Waters MF. Treatment of moderately severe erythema nodosum leprosum with clofazimine a controlled trial. Lepr Rev.1971;42(3):167-77.

9. Waters MF. An internally-controlled double blind trial of thalidomide in severe erythema nodosum leprosum. Lepr Rev.1971;42(1):26-42.

10. Use of thalidomide in leprosy. https://www.who.int/lep/research/ thalidomide/en/. Retrieved on 20-03-2020.

11. Risk Evaluation and Mitigation Strategies (REMS) for thalidomide. https://www.accessdata.fda.gov/scripts/cder/rems/index. cfm?event=IndvRemsDetails.page\&REMS=58. Retreived on 19-06-2020.

12. World health organisation (WHO). Promoting Rational Use of Medicines: Core Components - WHO Policy Perspectives on Medicines [internet].Geneva:WHO;2002.Available from: https://apps.who.int/ medicinedocs/en/d/Jh3011e/1.html.

13. Costa PDSS, Fraga LR, Kowalski TW, Daxbacher ELR, Schuler-Faccini L, Vianna FSL. Erythema Nodosum Leprosum: Update and challenges on the treatment of a neglected condition. Acta Trop. 2018;183:134-41.

14. Ishii N, Ishida Y, Okano Y, Ozaki M, Gidoh M, Kumano K, Goto M, Nogami R, Hatano K, Yamada A, Yotsu RR. Japanese guideline on thalidomide usage in the management of erythema nodosum leprosum. Nihon Hansenbyo Gakkai Zasshi. 2011;80(3):275-85.

15. Leon KE, Salinas JL, McDonald RW, Sheth AN, Fairley JK. Complex Type 2 Reactions in Three Patients with Hansen's Disease from a Southern United States Clinic. Am J Trop Med Hyg. 2015;93(5):1082-6.

16. Fogagnolo L, de Souza EM, Cintra ML, Velho PE. Vasculonecrotic reactions in leprosy. Braz J Infect Dis. 2007;11(3):378-82.

17. Rahul N, Sanjay KS, Singh S. Effectiveness of Methotrexate in prednisolone and thalidomide resistant cases of Type 2 lepra reaction: report on three cases. Lepr Rev. 2015;86(4):379-82.

18. Rattan R, Shanker V, Tegta GR, Verma GK. Severe form of type 2 reaction in patients of Hansen's disease after withdrawal of thalidomide: case reports. Indian J Lepr. 2009;81(4):199-203.

19. Shah A, Mahajan R, Ninama K, Bilimoria F. Annular bullous lesions with atypical erythema multiforme in leprosy. Lepr Rev. 2014;85(3):201-7.

20. Saber M, Bourassa-Fulop C, Bouffard D, Provost N. J Cutan Canadian case report of erythema nodosum leprosum successfully treated with prednisone and thalidomide. Med Surg. 2010;14(2):95-9.

21. Mahajan VK, Chauhan PS, Sharma NL, Sharma AL, Mehta KS. Severe vasculonecrotic erythema nodosum leprosum following thalidomide withdrawal without tapering doses: do we have something unusual?. Braz J Infect Dis. 2011;15(1):90-1 
22. Jitendra SSV, Bachaspatimayum R, Devi AS, Rita S.Azathioprine in Chronic Recalcitrant Erythema Nodosum Leprosum: A Case Report. J Clin Diagn Res. 2017;11(8):FD01-FD02.

23. Narang T, Kaushik A, Dogra S. Apremilast in chronic recalcitrant erythema nodosum leprosum: A report of two cases. Br J Dermatol. 2019 Jun 19. doi: 10.1111/bjd.18233. [Epub ahead of print]

24. Barman KD, Madan A, Garg VK, Goel K, Khurana N. Unusual Presentation of Necrotic Erythema Nodosum Leprosum on Scalp: A Case Report.Indian J Lepr. 2015;87(1):23-6.

25. Lindsey E, Richards BS, Mary E, Horner AM. A Papulo-Nodular Eruption With Systemic Signs and Symptoms. J Drugs Dermatol. 2015;14(4):422-3.

26. Rodríguez G, Abaúnza MC, Vargas EJ, López F. Leprosy and the testis. Biomedica. 2012;32(1):13-22.

27. Verma KK, Srivastava P, Minz A, Verma K. Role of azathioprine in preventing recurrences in a patient of recurrent erythema nodosum leprosum Lepr Rev. 2006;77(3):225-9.

28. Hosahalli Rajaiah Yogeesh HR, Sujatha Chankramath,Hari Kishan Kumar Yadalla, Shameem Shariff,Suhas Bettadapura Ramesh, Sapnashree Budhnoor Sreekantaiah. Type 2 Lepra Reaction (Enl) Presenting With Extensive Cutaneous Ulcerations. Our Dermatol Online. 2012;3(1):17-20.

29. Faber WR, Jensema AJ, Goldschmidt WF. Treatment of recurrent erythema nodosum leprosum with infliximab. $N$ Engl $J$ Med. 2006;355(7):739.

30. Hebe Petiti-Martin G, Villar-Buill M, de la Hera I, Fuertes L, BurguésCalderón M, Rivera-Díaz R, et al. Deep vein thrombosis in a patient with lepromatous leprosy receiving thalidomide to treat leprosy reaction. Actas Dermosifiliogr. 2013;104(1):67-70.

31. Vetrichevvel TP, Pise GA, Thappa DM. A case report of venous thrombosis in a leprosy patient treated with corticosteroid and thalidomide. Lepr Rev. 2008;79(2):193-5.

32. Chaudhry NS, Rath SR, Visvanath V, Torsekar RG. Our experience of the use of thalidomide in the steroid-dependent severe erythema nodosum leprosum. Indian J Dermatol Venereol Leprol. 2009;75(2): 189-90.

33. Santos JRS, Vendramini DL, Nery JADC, Avelleira JCR. Etanercept in erythema nodosum leprosum. An Bras Dermatol. 2017;92(4):575-7.
34. Gulanikar AD, Sharma S, Khare A. Bullous Erythema Nodosum Leprosum: A Rare Entity. Indian J Lepr. 2018;90(3):245-8.

35. Yamaguchi S, Yamamoto Y, Hosokawa A, Hagiwara K, Uezato H, Takahashi K. Deep venous thrombosis and pulmonary embolism secondary to co-administration of thalidomide and oral corticosteroid in a patient with leprosy. J Dermatol. 2012;39(8):711-4.

36. Sharma NL, Mahajan VK, Sharma VC, Sarin S, Sharma RC. Erythema nodosum leprosum and HIV infection: A therapeutic experience. Int J Lepr Other Mycobact Dis. 2005;73(3):189-93.

37. Singh SK, Sharma T, Rai T, Prabhu A.Type 2 lepra reaction in an immunocompromised patient precipitated by filariasis. Indian J Sex Transm Dis AIDS. 2014;35(1):40-2.

38. Panda PK, Prajapati R, Kumar A, Jana M, Immanuel P, Tanwar P, Wig N. A case of leprosy, erythema nodosum leprosum, and hemophagocytic syndrome: A continuum of manifestations of same agent-host interactions. Intractable \& Rare Diseases Research. 2017;6(3):230-33.

39. World health organisation (WHO): National list of essential medicine (2019) [internet]. Geneva; WHO, 2019. Available from: https://apps. who.int/iris/bitstream/handle/10665/325771/WHO-MVP-EMP-IAU2019.06-eng.pdf?ua $=1$.

40. Schuler-Faccini L, Soares RCF, de Sousa ACM, Maximino C, Luna E, Schwartz IVD, et al. New cases of thalidomide embryopathy in Brazil. Birth Defects Res A Clin Mol Teratol. 2007;79(9):671-2.

41. Vianna FSL, Oliveira MZ, Sanseverino MTV, Morelo EF, De Lyra Rabello Neto D, Lopez-Camelo J, et al. Pharmacoepidemiology and thalidomide embryopathy surveillance in Brazil. Reprod Toxicol. 2015;53:63-7.

42. Penna GO, Martelli CMT, Stefani MMA, Macedo VO, Maroja MF, Chaul A. Thalidomide in the treatment of erythema nodosum leprosum (ENL): systematic review of clinical trials and prospects of new investigations. An Bras Dermatol. 2005;80(5):511-22.

43. Ishii N, Ishida Y, Okano Y, Ozaki M, Gidoh M, Kumano K, et al. Guideline for clinical use of thalidomide for management of erythema nodosum leperosum in Japan. Jpn J Lepr. 2017;86(2):91-100.

44. Thalidomide.https://www.accessdata.fda.gov/drugsatfda_docs/ label/2003/20785slr022,023,024_thalomid_lbl.pdf.

45. World Health Organisation (WHO). Guidelines for the management of severe erythema nodosum leprosum (ENL) reactions. Geneva; WHO. Availabale from: https://www.who.int/lep/research/WHO enlguide.pdf. 
SUPPLEMENTARY TABLE 1: Rationale with respect to use of clofazimine in proposed dose and duration:

S.NO AUTHORS TREATMENT

$1 \quad$ Rahul nagar et al ${ }^{17} \quad \mathrm{I}$ - Prednisolone $40 \mathrm{mg} /$ day along with clofazimine $300 \mathrm{mgs} /$ day thalidomide was tapered below $100 \mathrm{mgs} / \mathrm{day}$.

II - prednisolone $40 \mathrm{mgs} /$ day, clofazimine $100 \mathrm{mgs}$ three times a day prednisolone in higher doses of $60 \mathrm{mgs} / \mathrm{day}$. Two successive thalidomide courses were also found

III - $60 \mathrm{mgs} /$ day prednisolone and $300 \mathrm{mgs} /$ day clofazimineTwo following courses of thalidomide

2. Shah et al ${ }^{19} \quad$ MDT + Oflox + Prednisolone. Ofl stopped, Clofazimine increased, Thalidomide included. $\begin{array}{ll}\text { 3. Mahajan } V K^{21} & \text { Treatment restarted with prednisone }(60 \mathrm{mg} / \text { day), clofazimine (100 mg three times/day), rifampicin (600 mg once a } \\ \text { month), thalidomide(100 } \mathrm{mg} \text { three times/day) }\end{array}$

4. Jitendra ssv et $\mathrm{al}^{22} \quad$ oral prednisolone $1 \mathrm{mg} / \mathrm{kg} /$ day

oral clofazimine $300 \mathrm{mg} /$ day for six months and $100 \mathrm{mg} /$ day for another six months. Thalidomide $200 \mathrm{mg} /$ day (STOPPED)

5. T. Narang et $a^{23} \quad$ After sufficient dose of clofazimine

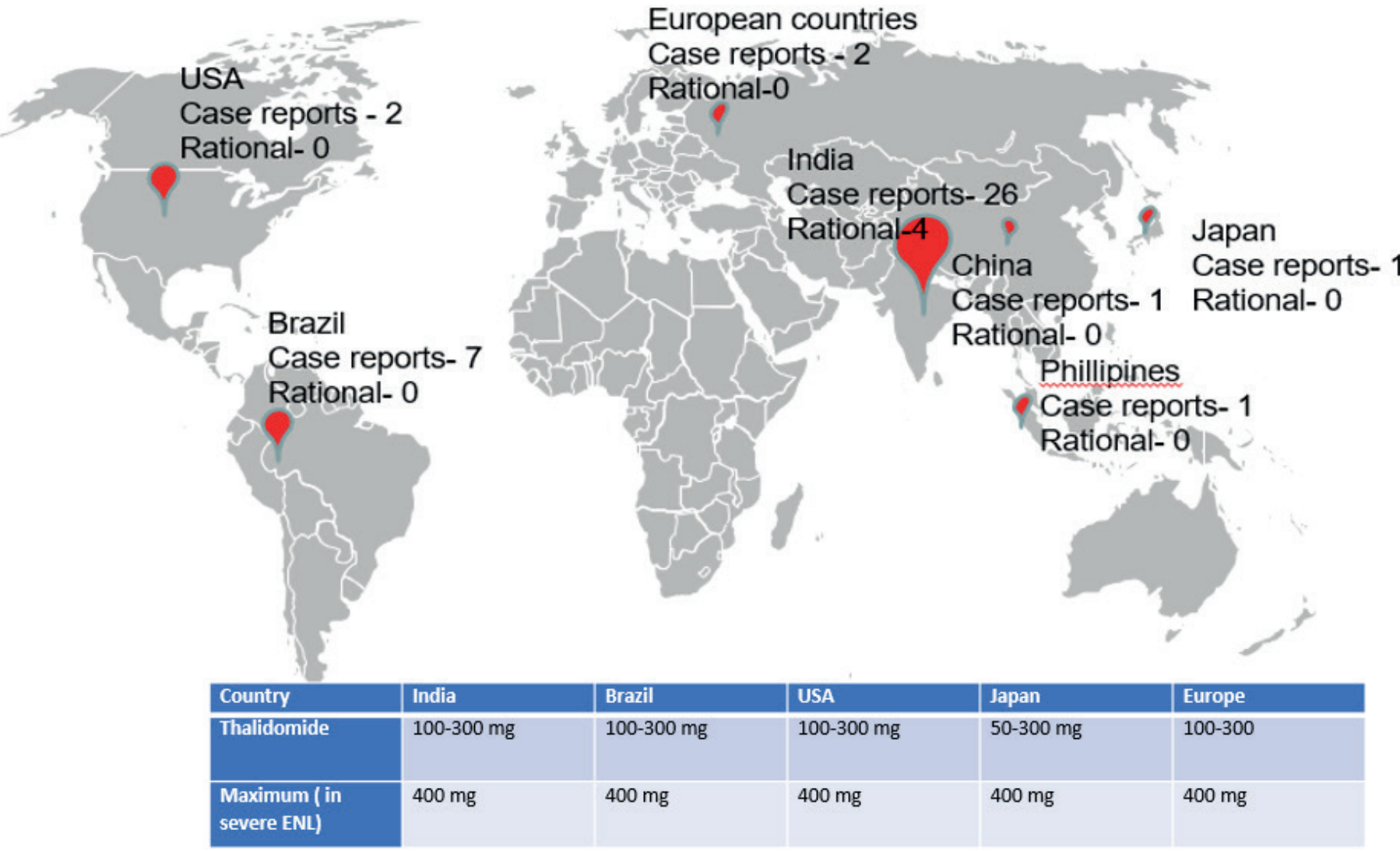

SUPPLEMENTARY FIGURE 1: World map showing case report distribution worldwide and the rational use of thalidomide in the case reports. 